\title{
The Same but Still Different: Forms in E-Government
}

\author{
Hendrik Scholta \\ University of Muenster - ERCIS, Muenster, Germany \\ hendrik.scholta@ercis.uni-muenster.de
}

\begin{abstract}
Forms are essential artifacts of government service delivery to transmit information between the customer and the government. However, customers perceive forms as too complex. Since the complexity of a system is influenced by the diversity of its components, this paper's main contribution is the identification of characteristics of forms and their components that drive the diversity of different forms. For this purpose, we evaluate a set of 69 forms of 27 German municipalities according to various criteria. The results reveal that different partitions of forms in subparts, varying sets of presented and requested data, different element types and varying captions for equal elements drive the complexity of current government forms. On the contrary, orders of elements are similar across the forms at hand.
\end{abstract}

\section{Introduction}

Forms are important artifacts in the course of government service delivery [6]. A form is an interface between the government and the customer to exchange information and collect relevant data [25]. Therefore, forms are main carriers of information [17] and input of government services [28] since they initiate a government service and contain the necessary data to deliver the service. Forms are views on data [31] since they prepare data to present it to external stakeholders.

However, although they are crucial for government service delivery, forms are still perceived as too complex by customers and have negative influence on the customers' satisfaction. In Germany, 56\% of the citizens complain about a low usability of egovernment services [14]. Although 60\% of German citizens take the opinion that forms are relevant for their satisfaction with government services, the citizens are not satisfied with the comprehensibility of forms [9]. In the United States, citizens desire simpler egovernment services and complain that too much information is requested from them [1].

Despite a reasonable amount of research on forms in general and in the course of e-government services in particular, an analysis of current government forms' degree of complexity and the complexity's influencing factors is missing in literature.

The complexity of a system is influenced by the diversity of its components and their relations [24]. In this paper, we focus on the diversity of the forms' components in the course of government service delivery. We investigate what characteristics of the forms' components drive the diversity of current forms. Forms have an inherent complexity that is defined by the regulations, laws and involved organizations of a service and cannot be eliminated. Besides, there is a high number of design guidelines to decrease complexity and increase user convenience of forms. Due to these two reasons, we do not aim at reducing the complexity of an individual form based on its underlying regulations and design guidelines. Instead, the systems at hand consist of a collection of forms of different municipalities for the same government service. Thus, we focus on the complexity that is driven by the diversity of different forms and their components.

Consequently, this paper answers the following research question: To what extent do current forms for the same government service in different German municipalities have a diverse structure (RQ1)? According to RQ1, we focus on the forms' structure and exclude the graphical arrangement of components from consideration. We answer the research question by analyzing the diversity of 69 current government forms according to a set of criteria. Thereby, we answer the following question: What characteristics of current government forms and their components drive their diversity (RQ2)? The answer of RQ2 helps to understand what initiatives should focus on when harmonizing forms.

The remainder of this paper is structured as follows: In section 2, we present related work of our research. Subsequently, section 3 explains our research design. In section 4 , we provide the results of our study. Section 5 discusses the results. Finally, we conclude and give an outlook on future work in section 6 . 


\section{Research Background}

\subsection{Form Representations and Structures}

"A form is an information holding object" [27, p. 500] and a context-specific view on data stored in a database $[31,36]$. In literature, there is a comprehensive amount of work specifying different levels of granularity on and components of forms $[22,27,30,34,35,36]$.

Analogously to [22,27], we distinguish between abstract forms, display forms and form instances. Abstract forms are models that abstract from concrete graphical design of forms but represent a form's fields and their order on the form, e.g. the field "Country" follows the field "State". An abstract form can be specialized by different display forms specifying design parameters, e.g. the creation of a HTML form for a government service with the specification of the field "Country" as drop-down menu. A form instance is an electronic or paper-based form that is filled with values for a certain case, e.g. the value "USA" is provided for the field "Country". The remainder of this paper will deal with display forms and their representation as abstract forms.

In addition to its name as heading, a form has a body with fields and groups [22]. To avoid ambiguity, we will refer to these groups as field groups in the following. Fields represent attributes of data entities and can be used to input and update data or present and output data [36]. A field can be further described with properties such as its caption, position on the form, data type such as integer, date or string, and the length of the field. Depending on the way fields are presented, the authors in [26] distinguish between tuple forms and relation forms. A tuple form consists of fields with captions for each data entity whereas in a relation form the data entities are displayed in a compressed table format. Recent research on web forms distinguishes different types of fields [4,33]: Text box, radio buttons, drop-down menu, list box and checkbox.

Whereas fields are the smallest units on a form, field groups are used to structure fields according to different subjects on the same level of abstraction (e.g. a differentiation between the field groups "name" and "address") or on the same subject but different levels of abstraction (e.g. the field group "applicant" consists of the field group "address"). Therefore, field groups are composites of fields and/or subordinate field groups [22].

\subsection{Forms in Action}

Before customers use forms in the course of egovernment services, they are developed by governments. For this purpose, many guidelines for the design of web forms can be applied [3,5,15,33]. The guidelines include design requirements considering the needs of increasingly aging users [21,23] or approaches to improve the accessibility of government forms for handicapped people [19]. Despite this research on designs of forms, their complexity is still an open issue. In order to cope with the remaining complexity, mechanisms such as automatic filling [32] and automatic completion [8] can support the customer during the completion of a form.

Diversity of components can be reduced through standardization if a standard is developed and implemented. "In the simplest sense, a standard is an agreed-upon way of doing something." [29, p. 1] Standardization in e-government is often discussed in terms of interoperability $[12,13,16,18]$. Since interoperability allows IT systems to exchange information, it describes an alternative interface to forms between governments and citizens and companies. Therefore, frameworks such as XÖV [7] are standards for interfaces between governments and customers and can serve as basis for the standardization of forms.

In addition to interoperability as first step for the standardization of forms, first dedicated concepts for this goal have been proposed. In [10], the authors present a role concept and process to standardize and manage forms in governments. In [2], a concept for the development of standardized information on services, processes and forms is introduced. However, these concepts are still to be implemented in practice.

\section{Research Design}

To investigate the diversity of forms in German municipalities, we applied a four-step approach that is visualized in figure 1: (1) Identification of suitable services and their initiating forms that are to be investigated, (2) Construction of comparable and abstract representations of the forms, (3) Development of groups consisting of elements with similar topics and functions across the forms and (4) Analysis of the diversity within the groups. The subjects of consideration are the municipalities of the 20 greatest German cities regarding population. Since there are federal states without a city that belongs to the 20 greatest cities, we additionally considered the capitals of those federal states. In total, we analyzed 27 municipalities.

In the course of step (1), we made a list of services for which most of the municipalities provide a reasonable amount of initiating forms on their websites. To apply a common understanding of what a service is, we used the terminology suggested by the 
LeiKa [11]. It is a standardized service catalogue for German governments that is managed by a government institution. Based on the list of potential services with a high amount of forms, we selected three services as target for our investigation. Our selection was guided by the following requirements: (a) The municipalities have to offer a high amount of forms for these services and (b) the main legal foundation for each selected service is defined on a different federal level. The result of this step is a set of application forms of 27 German municipalities for the initiation of three services. There can be more than one form per municipality if a municipality offers a PDF form and a web form.
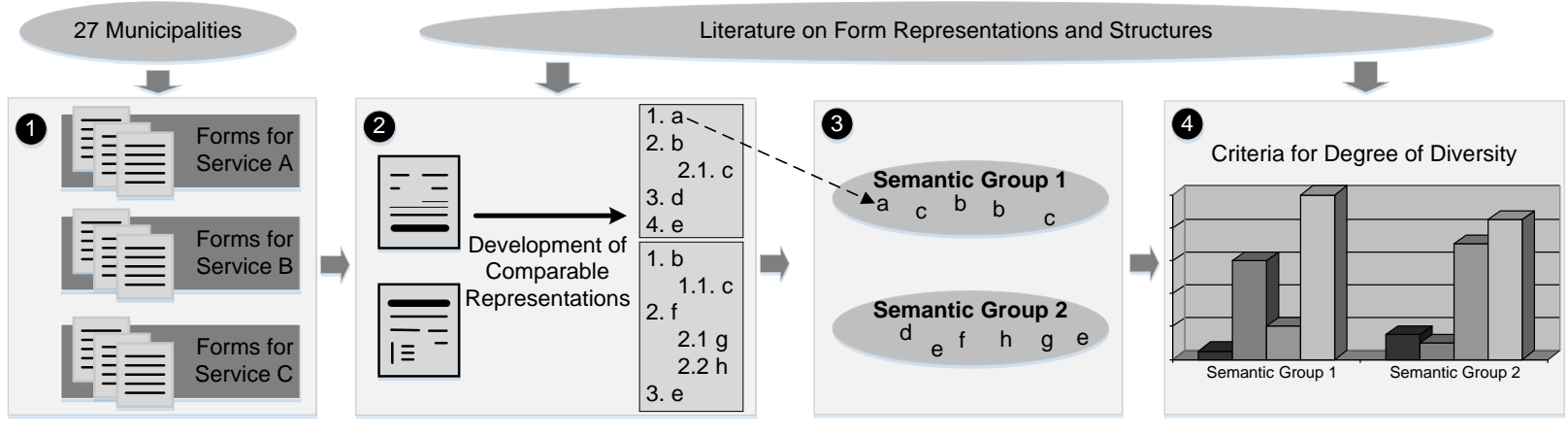

Figure 1. Research Design

In step (2), we developed abstract constructs for a uniform representation of the forms' structures and created a sequential abstract form for each display form. As forms differ in their graphical design, we had to map their display elements to standardized abstract elements to make the forms comparable and analyzable. For this purpose, we started deductively with abstract element types suggested in literature. To cover relevant differences of display elements, we refined the set of abstract element types inductively by applying the set iteratively to represent the display forms of step (1). After the last iteration, we used the final set of abstract element types to create abstract forms for the display forms at hand for succeeding processing. A single researcher created the final abstract forms to ensure consistency of the representations. The result of this step is twofold. First, a set of abstract element types that is used to represent the display forms abstracting from display details. Second, we transformed each display form to a sequential abstract form representing the form's display elements from the top to the bottom and from the left to the right.

Subsequently in step (3), we built groups of abstract elements for each service that have similar semantics, i.e. deal with the same topic and have the same function. We refer to these groups as semantic groups in the following. The topic indicates the realworld entity that is described by the abstract element whereas the function differentiates between abstract elements that present or capture information. We aimed at developing semantic groups with a disjoint meaning. In some cases, we had to assign an abstract element to more than one semantic group. For the forms of the first service, we inductively formed semantic groups by merging abstract elements or existing semantic groups based on the abstract elements' captions. We reused the first service's set of semantic groups during the creation of the semantic groups for the subsequent two services. We assigned the abstract elements to these groups and inductively created new semantic groups if necessary. The results of this step are semantic groups of abstract elements across all abstract forms of each service.

During step (4), the similarity of the abstract elements of each semantic group was analyzed to evaluate the diversity of the entire forms. If forms are homogenous, the abstract elements in the semantic groups do not only have similar semantics but also similar representative properties such as captions and positions. Based on characteristics of forms and knowledge gained during the previous steps, we developed a set of criteria and their computations to analyze the diversity. Then, we applied the criteria to the abstract forms of each service and their semantic groups. The result of this step is twofold: First, a set of criteria and potential drivers to evaluate the diversity of the abstract forms. Second, values for the criteria that indicate the diversity of each service's forms.

\section{Results}

\subsection{Step (1): Services}

In the course of step (1), we selected the following three services: A) Dog license fee registration, B) Issue 
of a certificate of eligibility for public housing and C) Registration at the residents' registration office.

The dog license fee is a municipal tax on dog keeping. It is collected annually for each dog. The legal foundations are municipal statutes and therefore defined on the third federal level. The municipalities are not forced to collect this tax. However, each of the municipalities at hand provides a registration form for the dog license fee. Two of the municipalities offer a PDF form and a web form. In total, there are 29 forms for the first service.

A certificate of eligibility for public housing confirms that a tenant is allowed to rent an accommodation in the course of subsidized housing. The applicants have to fulfil criteria such as upper limits for incomes that vary depending on the federal state. This is due to legal foundations that are defined on the second federal layer. Laws from the first federal layer only apply if federal states have not passed an own law. 21 of the municipalities at hand provide an application form for the second service.

Whenever a citizen moves to another city, a registration at the residents' registration office is obligatory. The same applies to citizens that obtain a residence in Germany for the first time. The legal foundations are specified on the first federal level. However, they can be extended on the second and third federal level. In total, 19 of the municipalities at hand offer a registration form on their websites.

\subsection{Step (2): Abstract Forms}

Table 1 presents the basic set of abstract element types that belongs to the first result of step (2) and was used to create abstract forms for the subsequent analyses. The abstract element types are categorized according to five categories. Category 1 contains abstract element types to represent different kinds of field groups: Tuple field group for tuple forms, Column group and Row group for relation forms.

The categories 2, 3 and 4 provide abstract element types for fields. Since fields are used to present data (e.g. the address of the municipality where the completed form has to be sent to) and capture data (e.g. the address of the applicant), we divide fields into output (category 2) and input (categories 3 and 4) fields. In addition to form headings, we observed form subheadings on the forms at hand. Labels present texts to users and graphics provide graphical illustrations such as logos.

Whereas category 3 covers abstract element types for different kinds of input fields on tuple forms, category 4 is dedicated to relation forms. In addition to the abstract element types suggested in literature, we added the abstract element type Cloze to category 3 .
Similarly to Text box, it allows users to enter free text. However, the captions are structured differently. In the case of a Cloze the input of the user is integrated into the caption whereas a Text box is separated from its caption, e.g. by a colon.

In category 4, a Table consists of Rows and Columns.

Table 1. Atomic abstract element types

Name Explanation/Example

Category 1: Field groups

\begin{tabular}{|c|c|c|c|c|}
\hline \multirow{3}{*}{$\begin{array}{l}\text { Tuple field } \\
\text { group }\end{array}$} & \multicolumn{4}{|c|}{ Tuple field group: } \\
\hline & \multicolumn{3}{|c|}{ Text box: } & \\
\hline & A cloze & \multicolumn{3}{|c|}{ is part of a sentence. } \\
\hline Column & \multicolumn{4}{|c|}{ Table: } \\
\hline group & & & \multicolumn{2}{|c|}{ Column group } \\
\hline \multirow{3}{*}{ Row group } & & & Column & Column \\
\hline & \multirow{2}{*}{$\begin{array}{l}\text { Row } \\
\text { group }\end{array}$} & Row & - & $\ldots$ \\
\hline & & Row & $\ldots$ & $\ldots$ \\
\hline
\end{tabular}

Category 2: Output fields

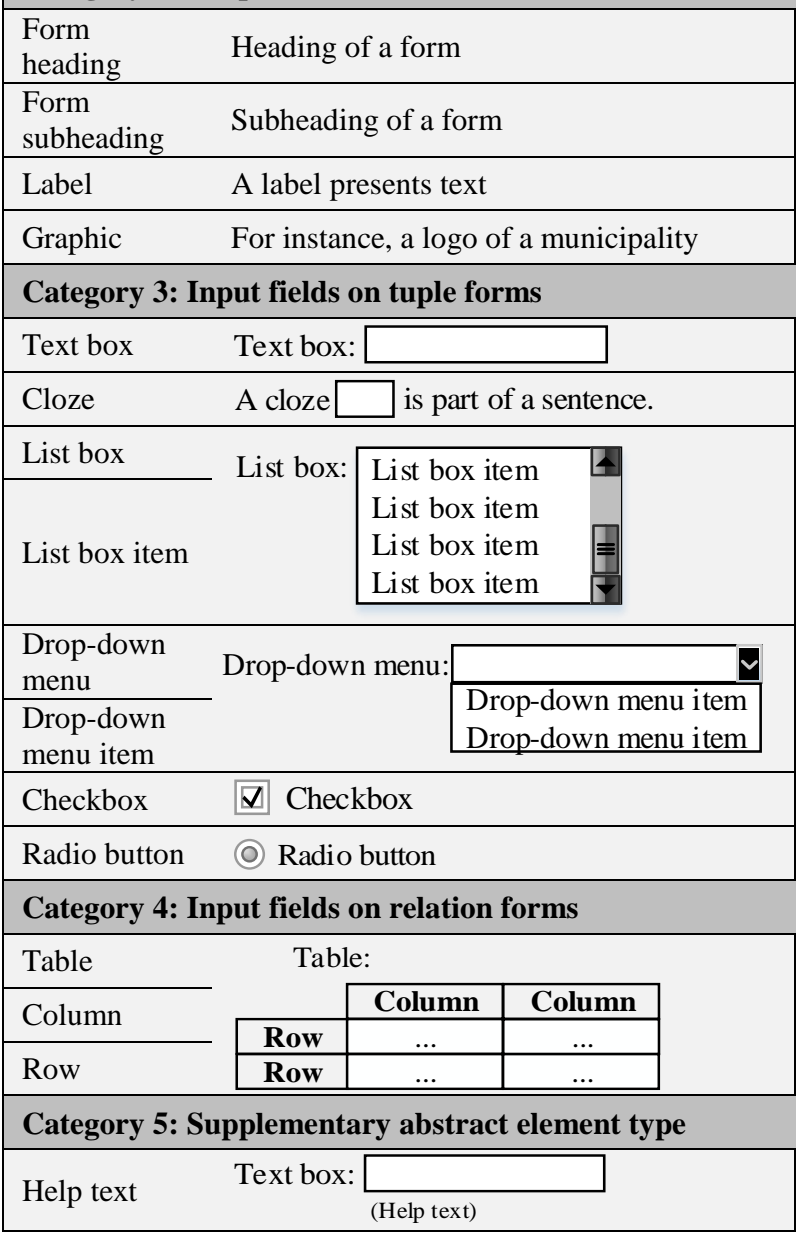

Abstract elements of the previously mentioned types can be enriched with supplementary information 
specified in category 5 . This category comprises the abstract element type Help text that enriches fields with information on what data has to be entered in which way.

The abstract element types from the field-related categories 2, 3 and 4 can be combined with abstract element types from all categories to composed abstract element types. The introduction of composed abstract element types is necessary to be able to represent the diversity of structural constructs that occur on the forms at hand and combine parts of fields, field groups and supplementary elements. Table 2 provides an excerpt of these types. In total, we identified 22 composed abstract element types on the forms at hand ${ }^{1}$.

Table 2. Excerpt of composed abstract element types

\begin{tabular}{|c|c|c|}
\hline Name & \multicolumn{2}{|l|}{ Example } \\
\hline $\begin{array}{l}\text { Text box } \\
\text { with help } \\
\text { text }\end{array}$ & \multicolumn{2}{|c|}{$\begin{array}{l}\text { The dog is being kept in your } \\
\text { household in [city] since: }\end{array}$} \\
\hline $\begin{array}{l}\text { Checkbox } \\
\text { with } \\
\text { cloze }\end{array}$ & \multicolumn{2}{|c|}{ D I moved from $\_$with the dog. } \\
\hline \multirow{2}{*}{$\begin{array}{l}\text { Checkbox } \\
\text { with tuple } \\
\text { field } \\
\text { group }\end{array}$} & \multirow{2}{*}{ acquired } & Previous owner surname, given name \\
\hline & & Address \\
\hline
\end{tabular}

The second result of step (2) is a set of abstract forms that are comparable representations of the forms' contents. To construct abstract forms, the display elements were mapped to according abstract elements of the types mentioned above. An exemplary display form excerpt and its abstract form equivalent are presented in figure 2 and table 3 . The excerpt comprises a single tuple field group. This tuple field group consists of eight elements, which is indicated by indents ( $2^{\text {nd }}$ structural layer). The gender of the dog is indicated by two checkboxes that are located on the $3^{\text {rd }}$ structural layer and grouped by a tuple field group.

\footnotetext{
${ }^{1}$ Composed abstract element types in addition to table 2: Text box with graphic, Text box with tuple field group, Text box with tuple field group and help text, Column with tuple field group, Row with text box, Row with tuple field group, Table with cloze, Cloze with help text, Cloze with tuple field group, Checkbox with help text, Checkbox with text box, Checkbox with text box and tuple field group, Checkbox with text box and help text, Checkbox with cloze and help text, Checkbox with cloze and tuple field group, Form heading with tuple field group, Form heading with checkbox and tuple field group, Form heading with checkbox and text box and help text, Radio button with help text.
}

Information regarding the $\mathrm{dog}$

\begin{tabular}{|l|l|l|}
\hline \multicolumn{2}{|l|}{ Breed } & \multicolumn{1}{l|}{ Involved breeds (if mixed-breed dog) } \\
\hline Dog's name & \multicolumn{2}{l|}{ Color } \\
\hline Date of birth & $\begin{array}{l}\text { Gender } \\
\nabla \text { male }\end{array}$ & Special characteristic or chip number \\
\hline How long have you been keeping the dog in [city]?
\end{tabular}

Figure 2. Exemplary display form excerpt

Table 3. The excerpt's representation as abstract form

\begin{tabular}{|c|c|c|c|}
\hline $1^{\text {st }}$ layer & $2^{\text {nd }}$ layer & $\begin{array}{l}3^{\text {rd }} \\
\text { layer }\end{array}$ & Type \\
\hline \multirow[t]{11}{*}{$\begin{array}{l}\text { Information } \\
\text { regarding } \\
\text { the dog }\end{array}$} & & & $\begin{array}{l}\text { Tuple field } \\
\text { group }\end{array}$ \\
\hline & Breed & & Text box \\
\hline & $\begin{array}{l}\text { Involved breeds } \\
\text { (if mixed-breed } \\
\text { dog) }\end{array}$ & & Text box \\
\hline & Dog's name & & Text box \\
\hline & Color & & Text box \\
\hline & Date of birth & & Text box \\
\hline & Gender & & $\begin{array}{l}\text { Tuple field } \\
\text { group }\end{array}$ \\
\hline & & male & Checkbox \\
\hline & & female & Checkbox \\
\hline & $\begin{array}{l}\text { Special } \\
\text { characteristic or } \\
\text { chip number }\end{array}$ & & Text box \\
\hline & $\begin{array}{l}\text { How long have } \\
\text { you been keeping } \\
\text { the dog in [city]? }\end{array}$ & & Text box \\
\hline
\end{tabular}

\subsection{Step (3): Semantic Groups}

In step (3), we created groups of abstract elements that have similar semantics. Due to consistency reasons, the semantic groups only contain abstract elements that occur on the first structural layer of the abstract forms. We identified generic semantic groups such as "Applicant" where the customer enters personal information. These groups are relevant to all three services. On the contrary, specific semantic groups such as "Landlord/Lessor" are dedicated to one specific service. Due to space limitations, we only consider generic semantic groups in the following. Table 4 presents the generic semantic groups as results of step (3). As stated in chapter 3, we describe each group by a topic and function. 
Table 4. Generic semantic groups

\begin{tabular}{|c|c|c|c|}
\hline No. & Topic & Function & Explanation \\
\hline 1 & $\begin{array}{l}\text { Administrative } \\
\text { procedure }\end{array}$ & Present & $\begin{array}{l}\text { Information regarding the procedure, e.g. upcoming steps, explanations of legal } \\
\text { specifications and guidelines }\end{array}$ \\
\hline 2 & Applicant & Capture & General information regarding the applicant, e.g. the name, address and date of birth \\
\hline 3 & Authentication & Capture & The applicant's signature and additional information such as the signature's date \\
\hline 4 & Case processing & Capture & $\begin{array}{l}\text { Fields that are filled by the authority after the applicant has submitted the form, e.g. } \\
\text { internal notes }\end{array}$ \\
\hline 5 & $\begin{array}{l}\text { Completeness and } \\
\text { correctness }\end{array}$ & Present & $\begin{array}{l}\text { Declaration that the applicant confirms the correctness and completeness of the } \\
\text { submitted information }\end{array}$ \\
\hline 6 & Delivered documents & Capture & The applicant indicates which documents are enclosed to the form \\
\hline 7 & Form's driving object & Capture & $\begin{array}{l}\text { The central object of the application or registration: The dog (service A), the } \\
\text { applicant (service B), the residence (service C) }\end{array}$ \\
\hline 8 & Form filling & Present & $\begin{array}{l}\text { Advices and guidelines on how to fill the form, e.g. a specification of the symbol } \\
\text { that indicates mandatory fields }\end{array}$ \\
\hline 9 & Form heading & Present & This group comprises the headings of the forms \\
\hline 10 & Form subheading & Present & This group contains the forms' subheadings \\
\hline 11 & Identification number & Capture & $\begin{array}{l}\text { The applicants may need to enter numbers that allow an identification, e.g. a tax } \\
\text { number }\end{array}$ \\
\hline 12 & Miscellaneous & Both & $\begin{array}{l}\text { This semantic group comprises all abstract elements that cannot be assigned to } \\
\text { another group, i.e. have a different semantic than other abstract elements }\end{array}$ \\
\hline 13 & Necessary documents & Present & Specification what proofs and certificates have to be enclosed to the form \\
\hline 14 & Privacy & Present & $\begin{array}{l}\text { Information on privacy regulations, e.g. legal foundations for data transfers to third } \\
\text { parties }\end{array}$ \\
\hline 15 & Public authority & Present & $\begin{array}{l}\text { General information of the form issuing institution, e.g. its address and opening } \\
\text { hours }\end{array}$ \\
\hline 16 & Supplementary notes & Capture & The applicant can enter additional free text to submit further remarks \\
\hline
\end{tabular}

\subsection{Step (4): Diversity of Forms}

To evaluate the diversity of forms, we derived criteria that are introduced in table 5.

\section{Table 5. Criteria for diversity of forms}

\section{Criterion I: Number of Forms}

Indicates how many forms are provided by the municipalities for a service and how many forms provide at least one abstract element that belongs to a certain semantic group. If the value for this criterion is low, then only a limited number of municipalities provides a form or certain content on the first structural layer.

\section{Criterion II: Average Number of Elements}

Determines the average number of abstract elements that an entire form or a part that belongs to a certain semantic group has on the first structural layer. If the values are high, then the forms have many abstract elements on the first structural layer.

\section{Criterion III: Dispersion of Number of Elements}

Calculates the standard deviation of the number of abstract elements on the first structural layer. If the values are high, then the forms follow different ways of partitioning forms since some use field groups to structure fields whereas others state fields directly on the first structural layer.
Criterion IV: Number of Different Element Types

Computes the number of different abstract element types on the first structural layer of entire forms and semantic groups with function "Capture". Semantic groups with function "Present" are excluded since there is essentially one type for output fields (label). If the values for this criterion are high, then the forms use different types to capture similar content

Criterion V: Number of Different Captions

Determines how many different captions exist for the abstract elements of a semantic group on the first structural layer. This number is divided by the number of abstract elements on the first structural layer to obtain the relative number of different captions per abstract element in the semantic group.

All semantic groups that contain long labels are excluded from the application of this criterion since texts can hardly be identical.

If the values are close to 1 , then every abstract element has a different caption and similar content is described differently on the forms at hand.

\section{Criterion VI: Variety of Captured Data}

Analyzes the forms' highest structural layers that request data from the applicant, i.e. contain input fields. Regarding the excerpt visualized in table 3, the second structural layer is analyzed since the first layer only contains a field group 
that structures the input fields of the second layer.

The criterion analyzes the equality of the data that is requested. For this purpose, we grouped similar abstract elements of the analyzed layers analogously to step (3) of the research design. The returned values indicate how many abstract elements belong to a group of one, two, three etc. If many abstract elements belong to small groups, then the requested data is different.

When applying this criterion, we considered semantic groups that capture information from the applicant and contain more than one abstract element per form. Analyses of sets are not meaningful if single elements are compared. Criterion VI.1 returns the number of abstract elements in groups with ten or less elements. Criterion VI.2 indicates the number of abstract elements that belong to a group with more than ten elements. Hence, if the value for VI.1 is low and the value for VI.2 is high, then equal data is requested.

\section{Criterion VII: Variety of Orders}

To evaluate the similarity of orders of fields that capture data and belong to a certain semantic group, we compare the orders of the abstract elements of one form to the order of abstract elements of a reference form. The reference form is the form that provides the most abstract elements for the semantic group. This criterion returns the average value of the pairwise comparisons.

Similarly to the Levenshtein distance [20] for strings, we compare orders by counting the minimal number of insertions, deletions and substitutions to transform one list of abstract elements to the list of the reference form. To exclusively focus on orders, we only take equal elements in both lists into account.

Since this criterion focuses on abstract elements that capture data from the applicant, it considers the same semantic groups and operates on the same structural layers as criterion VI.

A high value is returned, if the orders of the forms' elements for a certain semantic group highly differ to the order of the reference form.

We applied the criteria to the forms at hand and the semantic groups (SG). The evaluation results are presented in tables 6 and 7. The semantic groups are stated in the rows, whereas the criteria are mentioned in the columns. The values for the criteria are given for each of the services A, B and C.

According to the values for criterion I, the semantic group "Applicant" occurs on every form. Other frequent semantic groups are "Form's driving object" and "Form heading". However, there are semantic groups such as "Privacy" and "Form filling" that are only covered by some of the forms. The majority of the semantic groups appears on less than $50 \%$ of the forms.

Table 6. Application of the criteria - Part I

\begin{tabular}{|c|c|c|c|c|c|c|c|c|c|c|c|c|}
\hline Crit. & \multicolumn{3}{|c|}{ I } & \multicolumn{3}{|c|}{ II } & \multicolumn{3}{|c|}{ III } & \multicolumn{3}{|c|}{ IV } \\
\hline SG & A & B & $\mathrm{C}$ & A & B & $\mathrm{C}$ & A & B & $\mathrm{C}$ & A & B & $\mathrm{C}$ \\
\hline Form & 29 & 21 & 19 & 15.72 & 21.81 & 17.84 & 5.81 & 12.02 & 3.55 & 19 & 15 & 12 \\
\hline 1 & 16 & 10 & 13 & 1.44 & 1.4 & 1.46 & 0.73 & 0.7 & 0.52 & - & - & - \\
\hline 2 & 29 & 21 & 19 & 2.48 & 1.48 & 2.63 & 1.94 & 0.98 & 1.12 & 7 & 4 & 4 \\
\hline 3 & 24 & 14 & 18 & 1.79 & 2.5 & 1.94 & 0.88 & 1.22 & 0.87 & 2 & 3 & 1 \\
\hline 4 & 16 & 14 & 16 & 2.19 & 5.14 & 1.69 & 1.72 & 9.55 & 0.48 & 3 & 7 & 2 \\
\hline 5 & 9 & 15 & 0 & 1 & 1 & 0 & 0 & 0 & 0 & - & - & - \\
\hline 6 & 4 & 3 & 0 & 1 & 1 & 0 & 0 & 0 & 0 & 1 & 1 & 0 \\
\hline 7 & 27 & Cf. SG 2 & 19 & 2.29 & Cf. SG 2 & 1.68 & 1.84 & Cf. SG 2 & 1.29 & 10 & Cf. SG 2 & 6 \\
\hline 8 & 12 & 7 & 4 & 1 & 1.29 & 1.25 & 0 & 0.76 & 0.5 & - & - & - \\
\hline 9 & 28 & 21 & 18 & 1 & 1.1 & 1 & 0 & 0.3 & 0 & - & - & - \\
\hline 10 & 4 & 2 & 0 & 1.25 & 1 & 0 & 0.5 & 0 & 0 & - & - & - \\
\hline 11 & 9 & 1 & 1 & 1.11 & 1 & 1 & 0.33 & 0 & 0 & 2 & 1 & 1 \\
\hline 12 & 13 & 17 & 10 & 1.38 & 2 & 1.5 & 0.51 & 1.06 & 0.97 & - & - & - \\
\hline 13 & 2 & 7 & 0 & 1 & 1 & 0 & 0 & 0 & 0 & - & - & - \\
\hline 14 & 13 & 8 & 5 & 1.23 & 1.38 & 1.4 & 0.44 & 0.52 & 0.55 & - & - & - \\
\hline 15 & 25 & 17 & 3 & 2.04 & 2.35 & 1.67 & 1.27 & 1.27 & 1.15 & - & - & - \\
\hline 16 & 3 & 2 & 0 & 1 & 1 & 0 & 0 & 0 & 0 & 2 & 2 & 0 \\
\hline
\end{tabular}


Table 7. Application of the criteria - Part II

\begin{tabular}{|c|c|c|c|c|c|c|c|c|c|c|c|c|}
\hline Crit. & \multicolumn{3}{|c|}{$\mathbf{V}$} & \multicolumn{3}{|c|}{ VI.1 } & \multicolumn{3}{|c|}{ VI.2 } & \multicolumn{3}{|c|}{ VII } \\
\hline $\begin{array}{l}\text { Serv. } \\
\text { SG }\end{array}$ & A & B & $\mathrm{C}$ & A & B & $\mathrm{C}$ & A & B & $\mathrm{C}$ & A & B & $\mathrm{C}$ \\
\hline 2 & 0.89 & 0.9 & 0.24 & 99 & 157 & 135 & 171 & 70 & 363 & 0.1 & 0.15 & 0.13 \\
\hline 3 & 0.6 & 0.71 & 0.51 & 28 & 36 & 35 & 17 & 0 & 0 & 0.83 & 0 & 0 \\
\hline 7 & 0.68 & Cf. SG 2 & 0.41 & 187 & Cf. SG 2 & 52 & 73 & Cf. SG 2 & 61 & 0.51 & Cf. SG 2 & 0.22 \\
\hline 9 & 0.54 & 0.83 & 0.28 & - & - & - & - & - & - & - & - & - \\
\hline 10 & 0.8 & 1 & 0 & - & - & - & - & - & - & - & - & - \\
\hline 11 & $0.88^{*}$ & $0^{*}$ & $0^{*}$ & - & - & - & - & - & - & - & - & - \\
\hline 16 & 1 & 1 & 0 & - & - & - & - & - & - & - & - & - \\
\hline
\end{tabular}

*: The semantic group "Identification number" subsumes different numbers (A: 5, B: 1, C: 1). We applied criterion V to each single number that occurs more than once and state the average of these values for each service in the table. The value 0 indicates the nonexistence of a number which occurs more than once.

The criteria II and III indicate that the standard deviations for the number of elements on the first structural layer are high in relation to the averages for the majority of semantic groups and entire forms. For example, the standard deviation of "Applicant" (1.94) for service A is $78 \%$ of the average (2.48). Similarly, the standard deviation of the entire forms for service $\mathrm{B}$ is 12.02 and reaches $55 \%$ of the average (21.81). In contrast, for some semantic groups such as "Completeness and correctness" of service B the standard deviation is 0 .

The values for criterion IV provide insights on the number of different element types. The semantic groups "Form's driving object" and "Applicant" are the groups with the most different element types. The majority of the semantic groups incorporates three or less different element types. However, the entire forms use 12, 15 or 19 different abstract element types on the first structural layer. Dividing the number of element types by the number of forms reveals that more than every other form introduces a new abstract element type.

Regarding the services $\mathrm{A}$ and $\mathrm{B}$, the values for criterion $\mathrm{V}$ are close to 1 . When excluding semantic group 11 from consideration due to the different calculation, the lowest value for service $\mathrm{A}$ is 0.54 and the lower bound for service $\mathrm{B}$ is 0.71 . On the contrary, the values for service $\mathrm{C}$ are low with a maximum value of 0.51 .

The values for criterion VI are not unambiguous. The majority of the abstract elements of the semantic group "Authentication" does not have many equivalents on other forms (e.g. $36>0$ ). On the contrary, the other two semantic groups "Applicant" and "Form's driving object" have cases where many equivalent abstract elements exist (e.g. $135<363$ ) and cases where the majority does not have many equivalents (e.g. $187>73$ ).
Considering criterion VII, all values approximate 0 with two exceptions: One value is around 0.5 and one value is close to 1 . In consequence, the majority of values for criterion VII is low.

\section{Discussion}

Our results reveal that current forms in German municipalities have certain commonalities. However, there is a high diversity in their structure that results in complexity and can be addressed by harmonization initiatives. Table 8 contains a detailed discussion of the results and the diversity's driving factors.

\section{Table 8. Discussion of the results}

\section{Different Number of Partitions (Criteria II and III)}

The main form characteristic that drives complexity is the partition with different structural levels (criteria II and III). According to our results the standard deviations for the number of elements on the first layer are high in most cases. The standard deviation is low for labels since they present texts to users and do not require other elements. Consequently, the forms are partitioned differently.

Different Sets of Presented and Captured Data (Criteria I and $V I)$

According to criterion I, the contents on the first structural layer highly differ. Thus, the data that is presented to or captured from the customer is highly different across the forms. On the one hand, this may be obvious since the forms have different partitions as indicated by criteria II and III. If different partitions are used, then the data that is requested on the first structural on one form may be captured on the second layer of another form. Hence, the contents may be hidden by the structural layers and not discovered by criterion I. On the other hand, criterion VI indicates that despite certain commonalities there is potential for harmonization regarding the set of data that is captured by fields.

Different Element Types (Criterion IV)

According to the results for the semantic groups regarding 
criterion IV, in most cases the number of different element types is low in relation to the number of forms and the number of element types (41). However, considering the entire forms reveals that many different element types are used on the forms' first structural layer.

Different Captions (Criterion V)

Another characteristic that is relevant for the forms' diversity are different captions of elements. Although different elements should have different captions and the forms have many different elements as shown above, the values for criterion $\mathrm{V}$ are too close to 1 since the elements have similar semantics. Thus, there is potential to harmonize captions.

\section{Different Orders (Criterion VII)}

The results for criterion VII indicate that the average distances to the according reference forms are small with regard to orders. Consequently, criterion VII is not that relevant for harmonization initiatives at the moment since it indicates a low diversity. If the contents of current forms are similar, then also their orders are similar.

Taking everything into account, the absence of similar partitions, similar sets of presented and captured data, similar element types and equal captions for equal elements drives the diversity of current government forms. Orders are not a big issue at the moment. Most relevant are similar partitions. Initiatives should harmonize granularities and take into account the forms' modularity by providing harmonized building blocks that can be reused for different forms and services.

When harmonizing forms, initiatives should consider federal levels and their different legal foundations. Some differences in the forms' structures are defined by legal foundations. Consequently, the potential for harmonization is limited by legal foundations. However, there are cases such as the business registration in Germany where the legislator provides a template that can be used to create individual forms and thereby supports harmonization.

\section{Conclusion and Outlook}

In this paper, we analyzed to what extent current forms in German municipalities have a diverse structure. Additionally, we identified characteristics of current forms and their components that drive diversity. For the first time, we showed that form diversity is an important issue. Especially different partitions of forms should be targeted in the future.

This paper makes three contributions to research: First, the current list of abstract elements to represent display forms' structures can be applied for further analyses. Second, the generic semantic groups comprise contents that forms in general should contain and can be integrated into design guidelines. Third, the criteria to evaluate forms' diversity can be applied and extended in future research.

Additionally, we make two contributions to practice. First, we emphasized the need for form harmonization. Second, we identified characteristics of forms that should be focused by initiatives when harmonizing forms.

Despite its contributions, this paper is subject to limitations and potential for future work. First, we only considered the generic semantic groups and excluded the specific semantic groups from the paper. Although an integration of these semantic groups reveals a more comprehensive view on the diversity of forms, the open issues for harmonization remain the same. Second, since the selection of the reference form influences the values for criterion VII, more sophisticated calculations can be developed for this criterion in the future. Third, a similarity measure for forms may be constructed by integrating and weighting the criteria into one figure. Fourth, in this paper we developed criteria that are applied to individual services. In the future, further criteria for inter-service comparisons can be developed and calculated.

We raised the need for a harmonization of forms. It is the task of researchers to conceptualize and support initiatives that are dedicated to this issue with their method and domain knowledge.

\section{Acknowledgment}

I would like to thank Annika Verhorst for her support during the creation of this paper.

\section{References}

[1] Accenture. Digital Government: Your Digital Citizens are Ready, Willing... and Waiting. 2015. https://www.accenture.com/t20151014T210834_w__/usen/_acnmedia/Accenture/Conversion-

Assets/DotCom/Documents/Global/PDF/Dualpub_16/Acce nture-Your-Digital-Citizens-Ready-Willing-Waiting-2.pdf [Accessed: 03-Mar-2016].

[2] Ahrend, N., Wolf, P., Räckers, M., Dentschev, A., and Jurisch, M. Federal Information Management - Context and Effects. Proceedings of the 44. Jahrestagung der Gesellschaft für Informatik, Stuttgart, (2014), 1499-1511.

[3] Axelsson, K. and Ventura, S. Reaching Communication Quality in Public E-Forms - A Communicative Perspective on E-Form Design. Proceedings of the 6th International Conference on Electronic Government, Regensburg, (2007), 342-353.

[4] Bargas-Avila, J.A., Brenzikofer, O., Roth, S.P., Tuch, A.N., Orsini, S., and Opwis, K. Simple but Crucial User Interfaces in the World Wide Web: Introducing 20 Guidelines for Usable Web Form Design. In R. Mátrai, ed., 
User Interfaces. InTech, 2010, 1-10.

[5] Bargas-Avila, J.A., Oberholzer, G., Schmutz, P., de Vito, M., and Opwis, K. Usable error message presentation in the World Wide Web: Do not show errors right away. Interacting with Computers 19, 3 (2007), 330-341.

[6] Becker, J., Algermissen, L., and Falk, T. Modernizing Processes in Public Administrations: Process Management in the Age of e-Government and New Public Management. Springer-Verlag, Berlin, Heidelberg, 2012.

[7] Büttner, F., Bartels, U., Hamann, L., et al. Model-driven standardization of public authority data interchange. Science of Computer Programming 89, (2014), 162-175.

[8] Chaudhuri, S. and Kaushik, R. Extending Autocompletion To Tolerate Errors. Proceedings of the ACM SIGMOD International Conference on Management of Data, Providence, (2009), 707-718.

[9] Federal Statistical Office. Zufriedenheit der Bürgerinnen und Bürger in Deutschland mit behördlichen Dienstleistungen: Ausgewählte Ergebnisse der Zufriedenheitsbefragung 2015. 2015. https://www.amtlicheinfach.de/SharedDocs/Downloads/Ergebnisse_Buerger.pd $\mathrm{f}$ ?__blob=publicationFile \&v=3 [Accessed: 16-Feb-2016].

[10] Folmer, E., Matzner, M., Räckers, M., Scholta, H., and Becker, J. Standardized but Flexible Information Exchange for Networked Public Administrations - A Method. Transforming Government: People, Process and Policy 10, 2 (2016).

[11] Geschäfts- und Koordinierungsstelle LeiKa. LeiKa. 2015. http://leika.zfinder.de [Accessed: 16-Oct-2015].

[12] Gottschalk, P. Maturity levels for interoperability in digital government. Government Information Quarterly 26, 1 (2009), 75-81.

[13] Guijarro, L. Interoperability frameworks and enterprise architectures in e-government initiatives in Europe and the United States. Government Information Quarterly 24, 1 (2007), 89-101.

[14] Initiative D21 and ipima. eGovernment Monitor 2015. 2015. http://www.egovernment-monitor.de/die-

studie/2015.html [Accessed: 01-Dec-2015].

[15] Jarrett, C. and Gaffney, G. Forms that Work: Designing Web Forms for Usability. Morgan Kaufmann, Burlington, 2009.

[16] Klischewski, R. and Scholl, H.J. Information quality as a common ground for key players in e-government integration and interoperability. Proceedings of the 39th Hawaii International Conference on System Sciences, Kauai, (2006), 1-10.

[17] Klischewski, R. Ontologies for e-document management in public administration. Business Process Management Journal 12, 1 (2006), 34-47.

[18] Kubicek, H. and Cimander, R. Three dimensions of organizational interoperability: Insights from recent studies for improving interoperability frame-works. European Journal of ePractice 6, (2009), 3-14.

[19] Kuhn, N., Richter, S., Schmidt, M., and Truar, A. Improving Accessibility to Governmental Forms. Proceedings of the 1st TC 13 Human-Computer Interaction Symposium, Milano, (2008), 119-128.

[20] Levenshtein, V.I. Binary Codes Capable of Correcting Deletions, Insertions and Reversals. Soviet physics-doklady 10, 8 (1966), 707-710.
[21] Lines, L., Ikechi, O., and Hone, K.S. Accessing eGovernment Services: Design Requirements for the Older User. Proceedings of the 4th International Conference on Universal Access in Human-Computer Interaction, Beijing, (2007), 932-940.

[22] Lum, V.Y., Choy, D.M., and Shu, N.C. OPAS: An office procedure automation system. IBM Systems Journal 21, 3 (1982), 327-350.

[23] Money, A.G., Lines, L., Fernando, S., and Elliman, A.D. e-Government online forms: design guidelines for older adults in Europe. Universal Access in the Information Society 10, 1 (2011), 1-16.

[24] Page, S.E. Diversity and Complexity. Princeton University Press, New Jersey, 2011.

[25] Papadomichelaki, X. and Mentzas, G. e-GovQual: A multiple-item scale for assessing e-government service quality. Government Information Quarterly 29, 1 (2012), 98-109.

[26] Rowe, L.A. and Shoens, K.A. A Form Application Development System. Proceedings of the 1982 ACM SIGMOD International Conference on Management of Data, Orlando, (1982), 28-38.

[27] Shu, N.C., Lum, V.Y., Tung, F.C., and Chang, C.L. Specification of Forms Processing and Business Procedures for Office Automation. IEEE Transactions on Software Engineering SE-8, 5 (1982), 499-512.

[28] Sourouni, A.-M., Lampathaki, F., Mouzakitis, S., Charalabidis, Y., and Askounis, D. Paving the Way to eGovernment Transformation: Interoperability Registry Infrastructure Development. Proceedings of the 7th International Conference on Electronic Government, Turin, (2008), 340-351.

[29] Spivak, S.M. and Brenner, F.C. Standardization Essentials: Principles and Practice. Marcel Dekker, New York, 2001.

[30] Tsichritzis, D. Form Management. Communications of the ACM 25, 7 (1982), 453-478.

[31] van der Aalst, W.M.P., Weske, M., and Grünbauer, D. Case handling: a new paradigm for business process support. Data \& Knowledge Engineering 53, 2 (2005), 129-162.

[32] Winckler, M., Gaits, V., Vo, D.-B., Firmenich, S., and Rossi, G. An approach and tool support for assisting users to fill-in web forms with personal information. Proceedings of the 29th ACM international conference on Design of communication, Pisa, (2011), 195-202.

[33] Wroblewski, L. Web Form Design: Filling in the Blanks. Rosenfeld Media, Brooklyn, New York, 2008.

[34] Wu, J.-H., Doong, H.-S., Lee, C.-C., Hsia, T.-C., and Liang, T.-P. A methodology for designing form-based decision support systems. Decision Support Systems 36, 3 (2004), 313-335.

[35] Wu, J.-H. A visual approach to end user form management. Journal of Computer Information Systems 41, 1 (2000), 31-39.

[36] Yao, S.B., Hevner, A.R., Shi, Z., and Luo, D. FORMANAGER: An Office Forms Management System. ACM Transactions on Office Information Systems 2, 3 (1984), 235-262. 